\title{
Aircraft and ground measurements of dust aerosols over the west African coast in summer 2015 during ICE-D and AER-D
}

\section{Liu et al.}

Correspondence to: Dantong Liu (dantong.liu@ manchester.ac.uk)

The copyright of individual parts of the supplement might differ from the CC BY 4.0 License. 

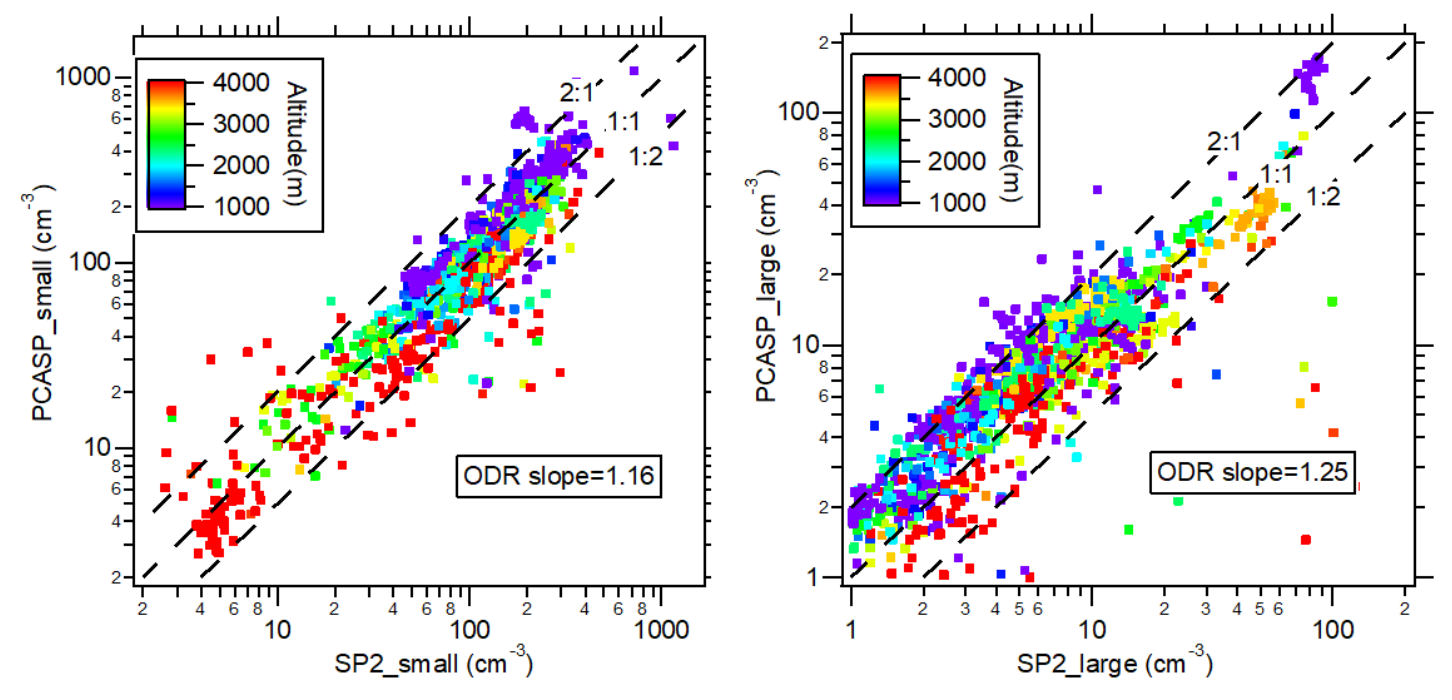

Fig. S1. Comparison between SP2 and PCASP measured number concentration at $0.18-0.5 \mu \mathrm{m}$ and $0.5-2.5 \mu \mathrm{m}$ respectively for all flights, coloured by the altitude. The concentrations from both instruments are reported at standard temperature and pressure (STP, 273.15K and 1013.25 mbar).

\section{The measurement of hematite by the SP2}
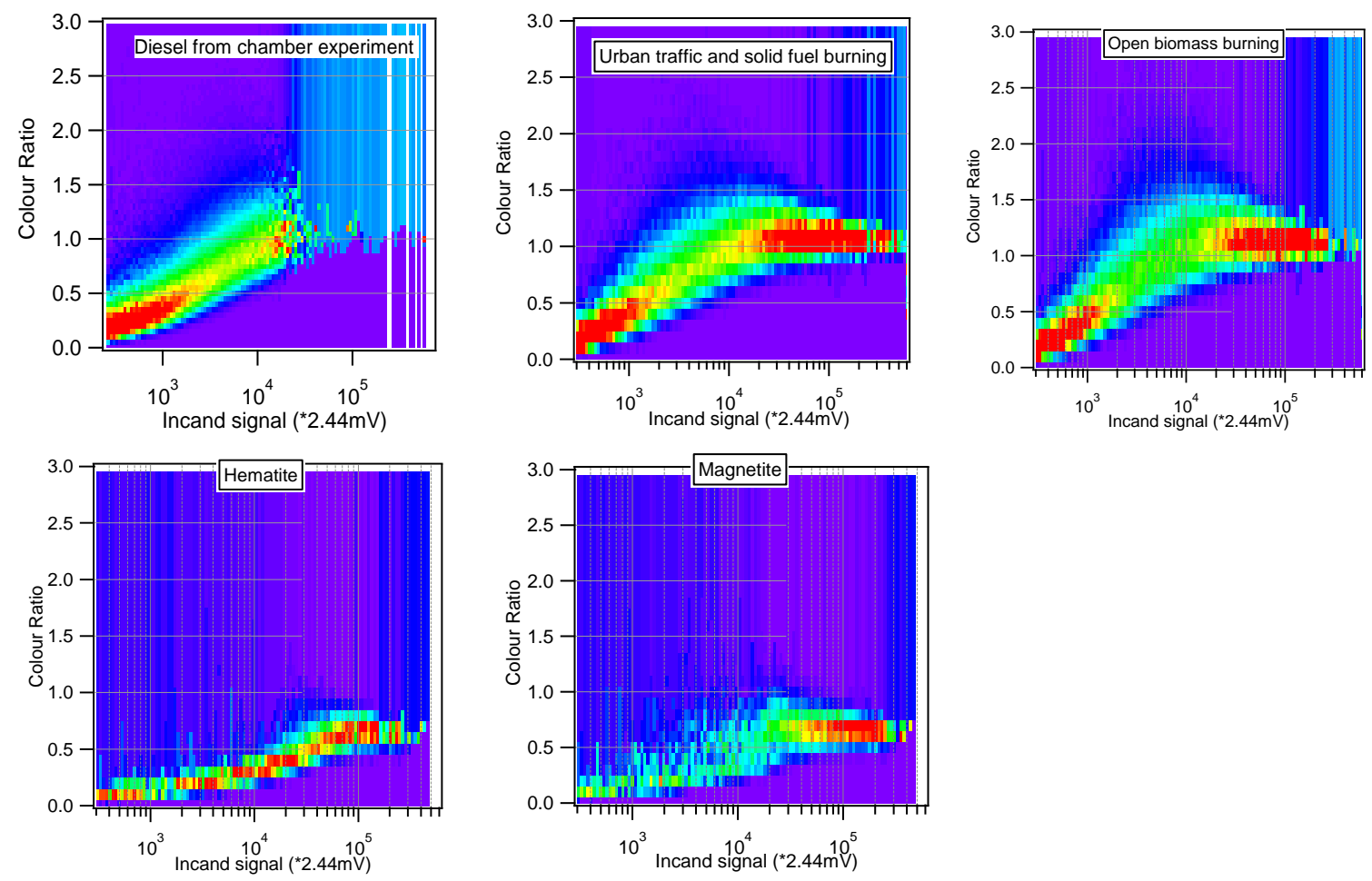

Fig. S2. The colour ratio as a function of broadband signal for BC from a range of sources and for absorbing iron oxides (Hematite and Magnetite).

The response of the SP2 to the dust sample was calibrated in the laboratory using mass-selected pure magnetite and hematite. The SP2 incandescence signal as a function of particle mass is fitted using a power function in the order of particle surface area, based on the theory that the emission cross section of a particle is proportional to the surface area $\left(\mathrm{m}^{2 / 3}\right)$ when the particle size is significantly 
larger than the wavelength 1064nm (Yoshida et al., 2016); whereas for the small BC the irradiation is proportional to the particle mass $(\mathrm{m})$. For the smaller masses below $100 \mathrm{fg}$, the incandescence signal is above the $\mathrm{m}^{2 / 3}$ fitting line because the irradiance emission is closer to the order of $m$. The detection efficiency of the SP2 at each particle mass is obtained by comparing the counts of incandescence and scattering-only non-incandescence particles.

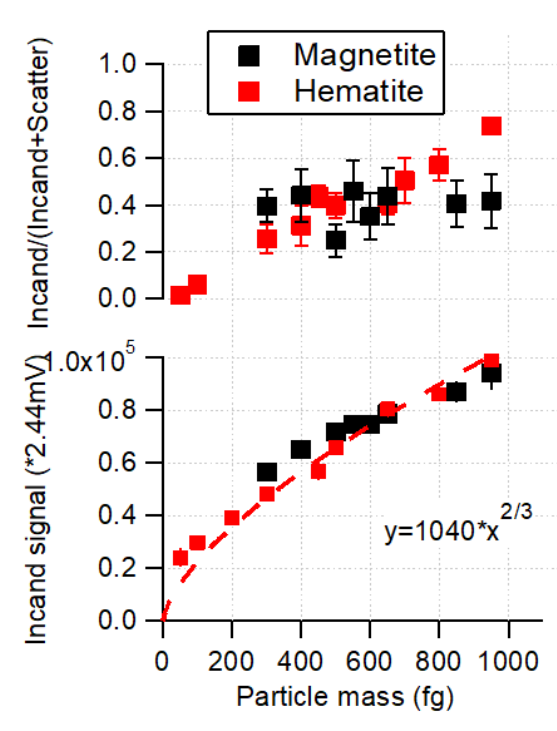

Fig. S3. The SP2 broadband incandescence signal as a function of particle mass for hematite and magnetite; the detection efficiency at each particle mass. 

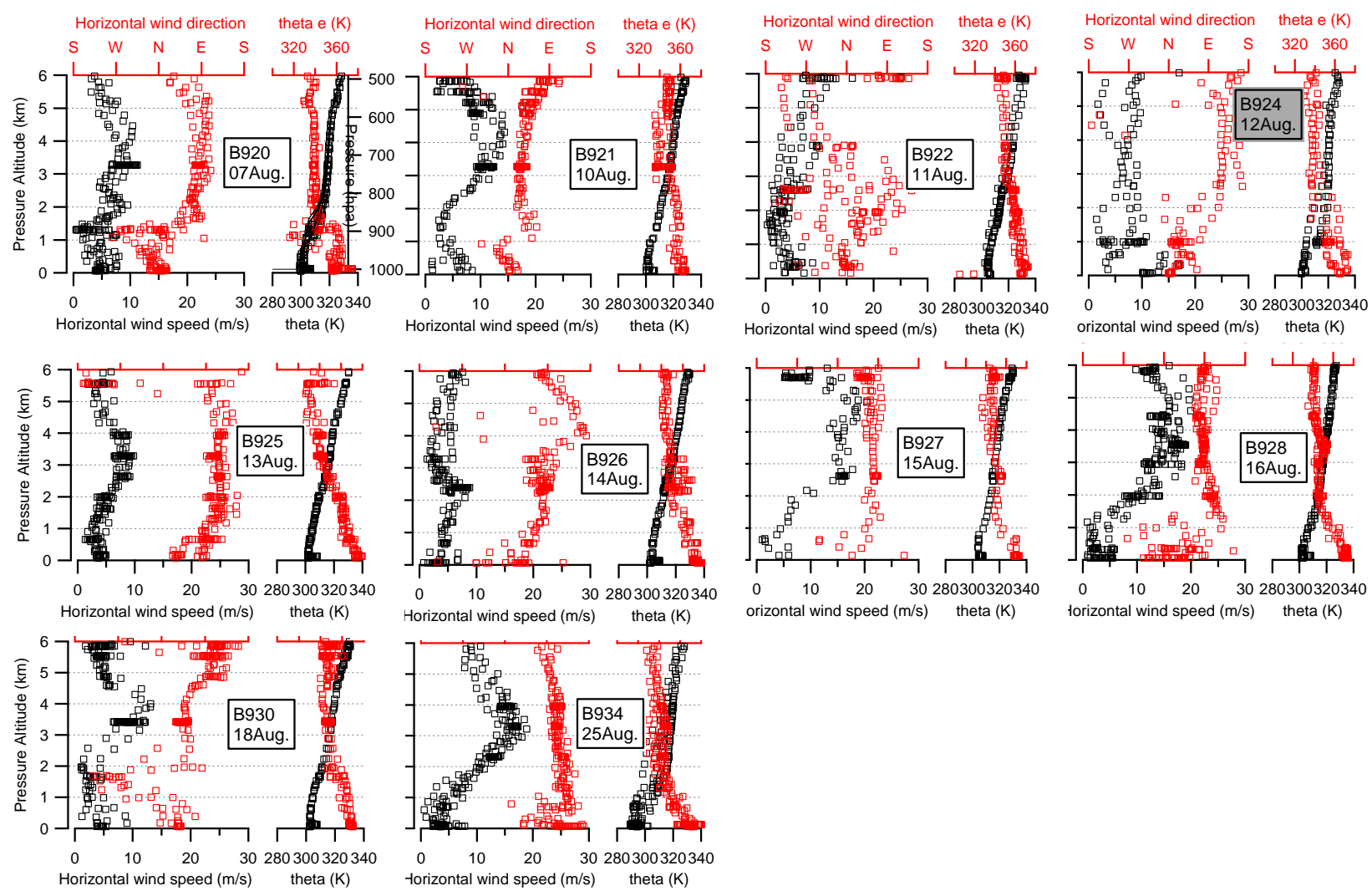

orizontal wind speed $(\mathrm{m} / \mathrm{s}) \quad$ theta $(\mathrm{K})$

torizontal wind speed $(\mathrm{m} / \mathrm{s})$ theta $(\mathrm{K})$

Fig. S4. The in-situ measurements of wind speed, win direction, potential temperature $(\theta)$, and moist equivalent potential temperature $\left(\theta_{e}\right)$. The transition flight (B923), flight without AMS running (B929), and the cloud flights without aerosol profile or SLR (B931-B933) are excluded from the analysis here. 
16/08/2015 18:00
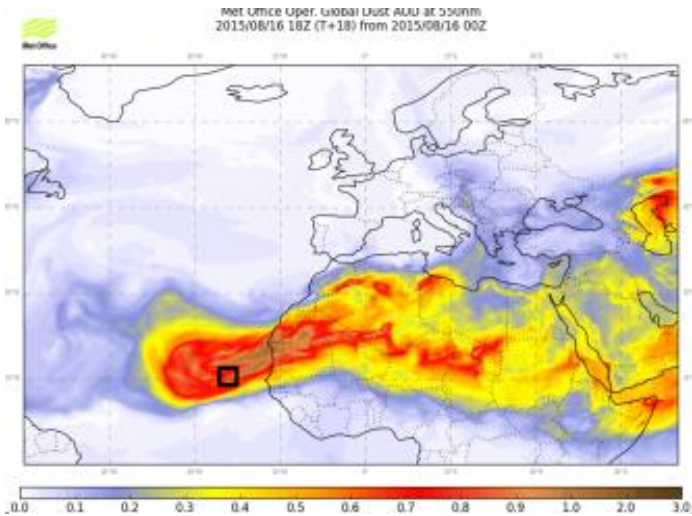

11/08/2015 18:00 (-5days)
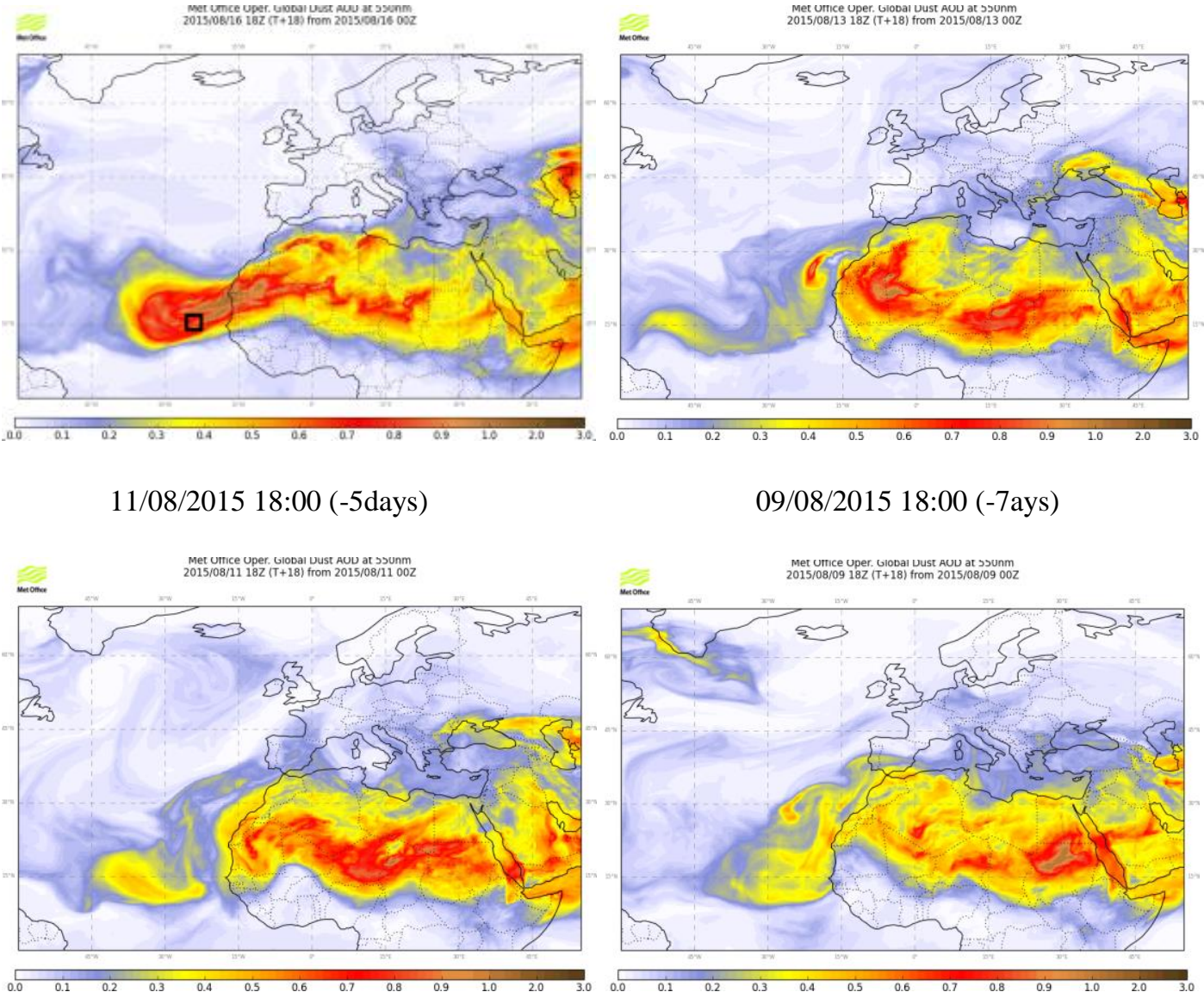

09/08/2015 18:00 (-7ays)

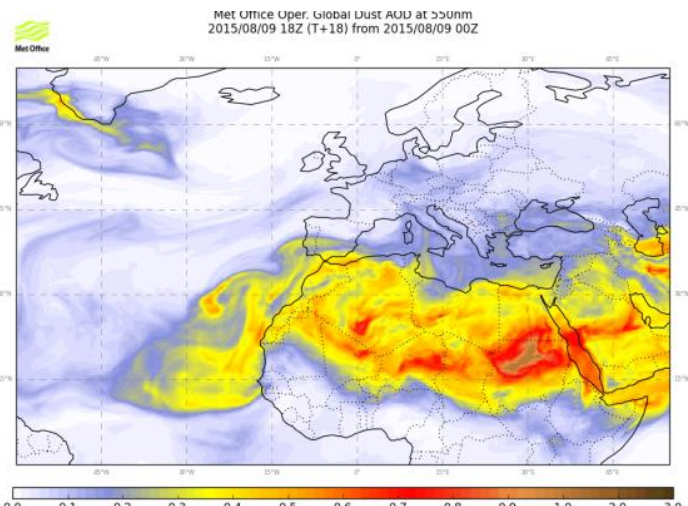

$5 \quad$ Fig. S5. The dust aerosol optical depth (AOD) distribution from the Met Office forecast model leading up to $16^{\text {th }}$ Aug. of flight B928. The open square makers the location of Cabo Verde. 
The cross section sub-type aerosol product from CALIPSO (The Cloud-Aerosol Lidar and Infrared Pathfinder Satellite Observation)

13/08/2015 (-3days)
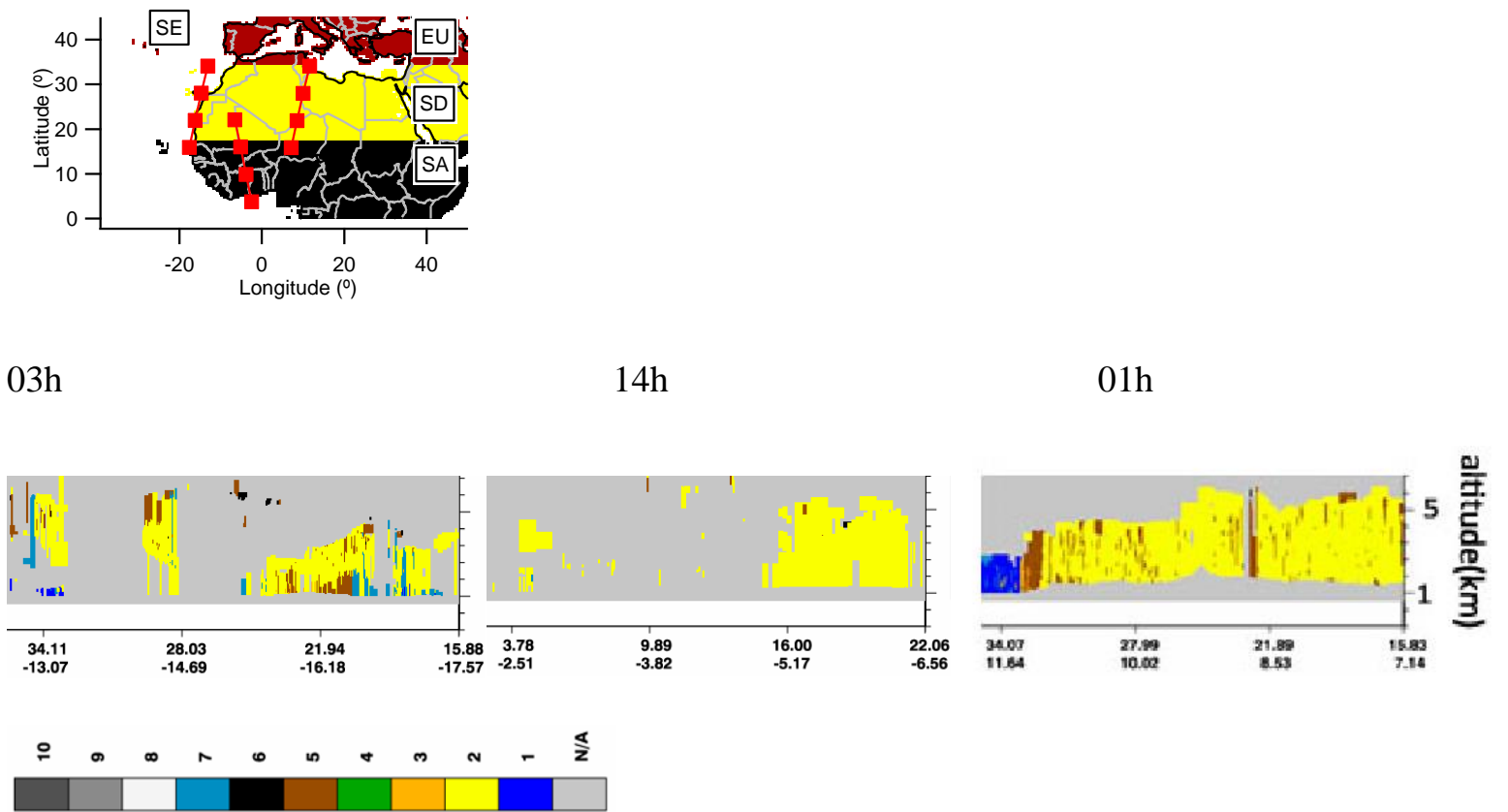

N/A = not applicable $\quad 1=$ marine $2=$ dust $3=$ polluted continental $/$ smoke

4 = clean continental $5=$ polluted dust $6=$ elevated smoke $\quad 7=$ dusty marine

$8=$ PSC aerosol $9=$ volcanic ash $10=$ sulfate $/$ other

$11 / 08 / 2015$ (-5 days)
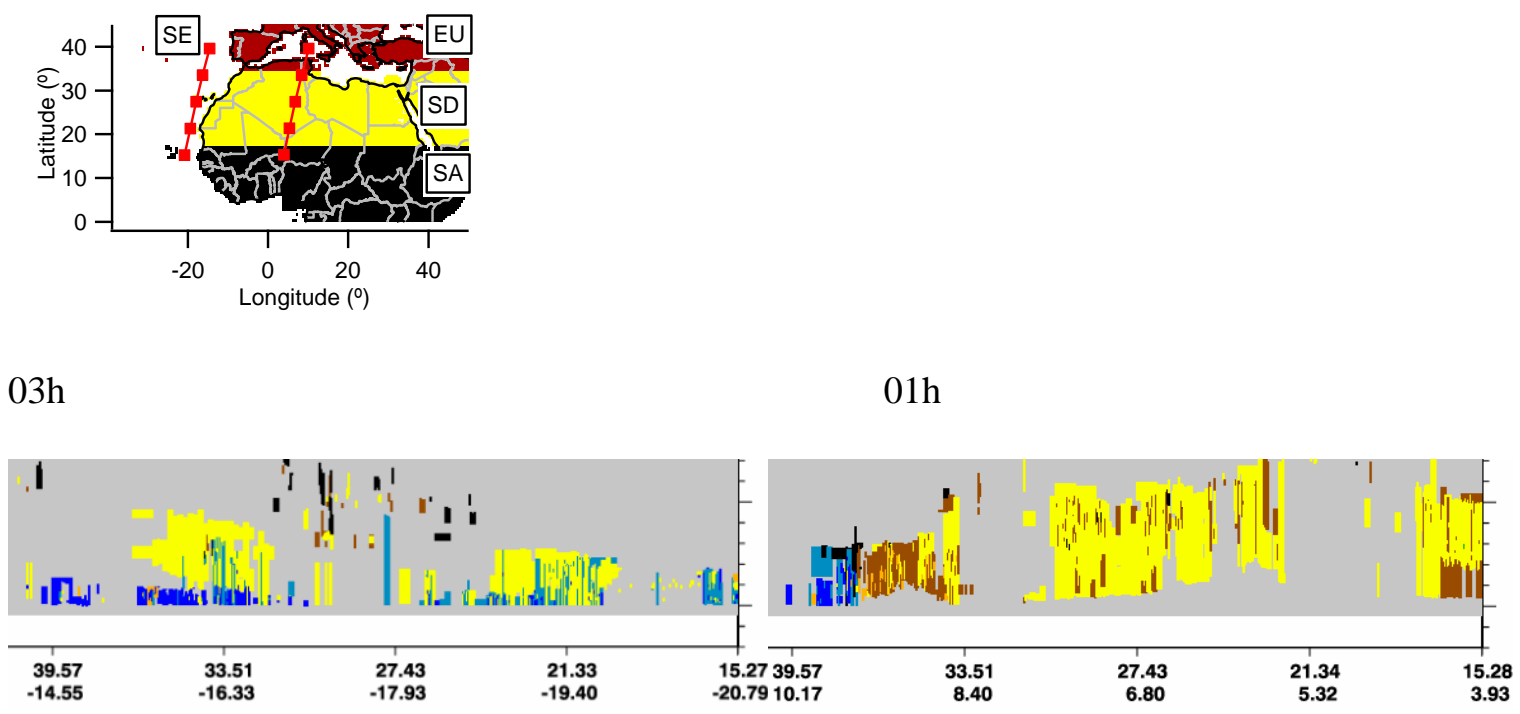


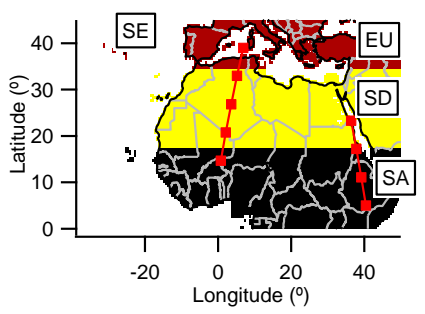

$02 \mathrm{~h}$

$11 \mathrm{~h}$

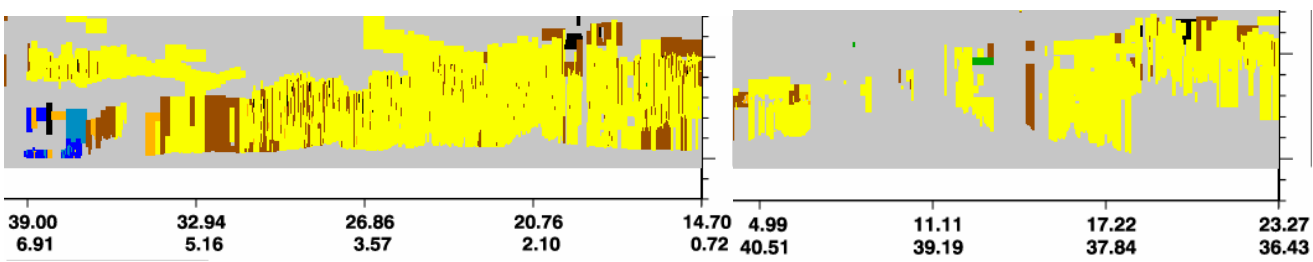

5 Fig. S6. The CALIPSO sub-type aerosol cross sections from $16^{\text {th }}$ Aug. backwards up to 7 days, corresponding to the BT pathways for flight B928. The red lines on the map denote the satellite orbit track for each sub-figure, and each marker conresponds with the locations of the $\mathrm{x}$-axis of the subfigure.

The backtrajectory analysis for all of the flights
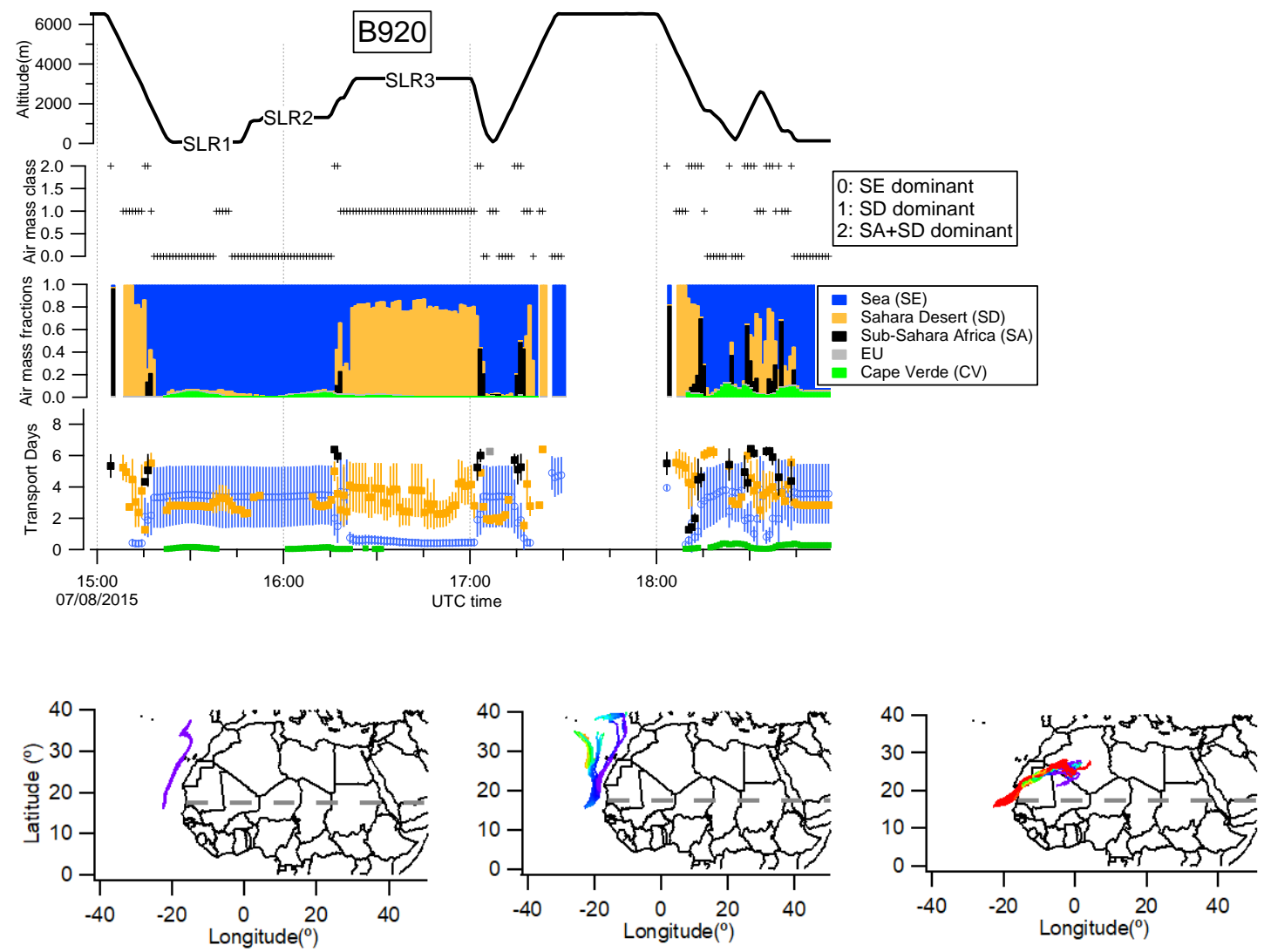

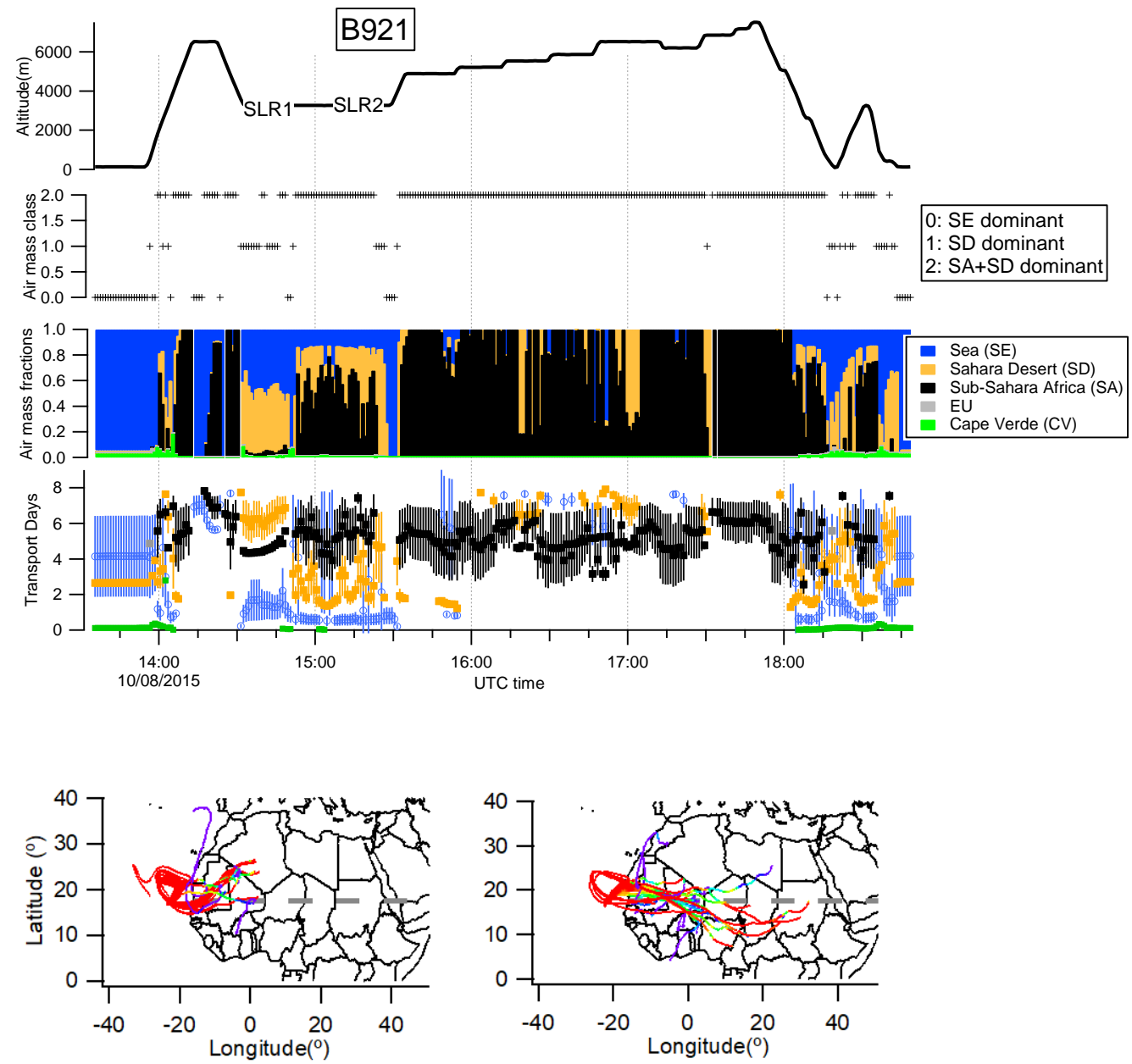

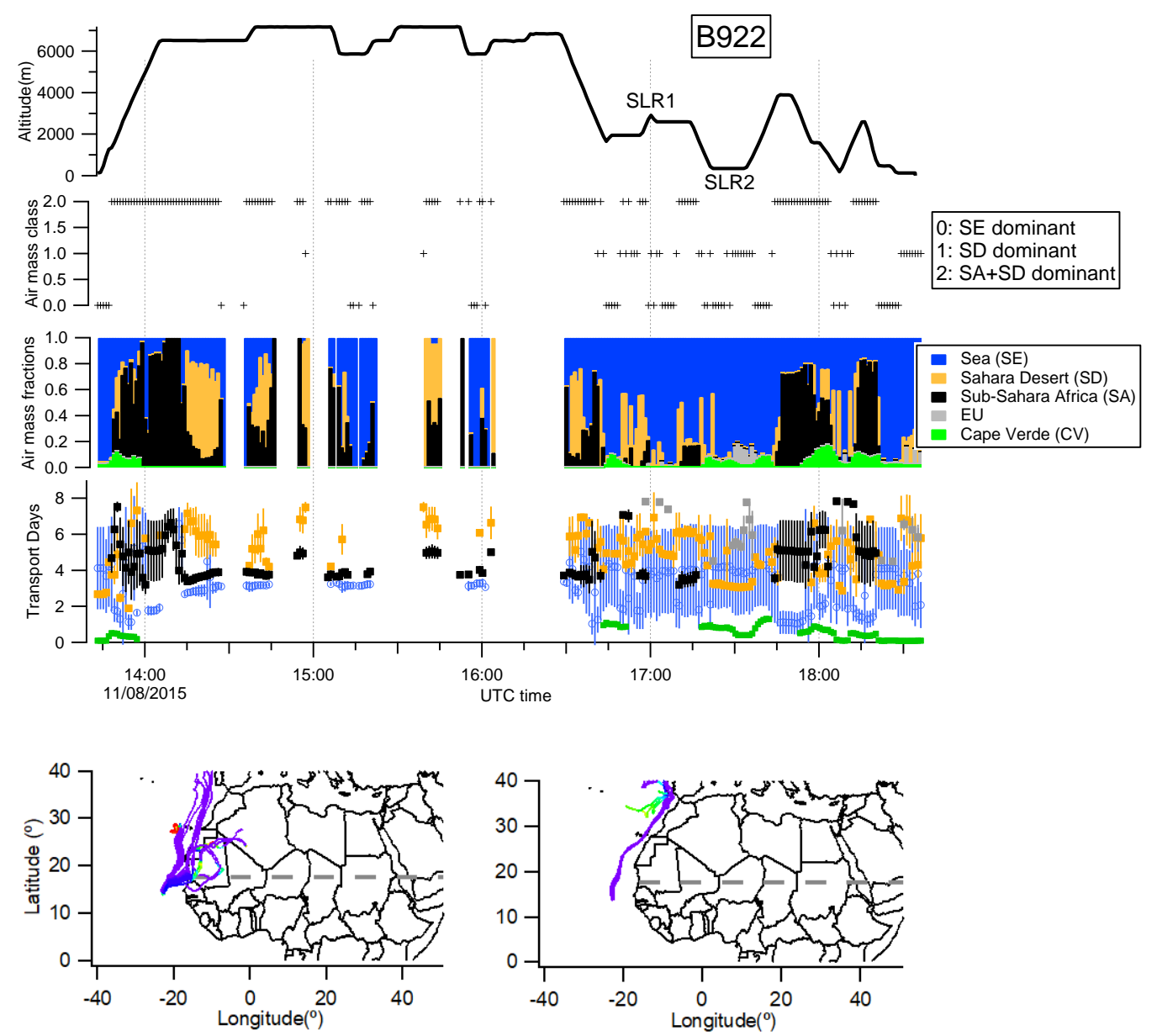

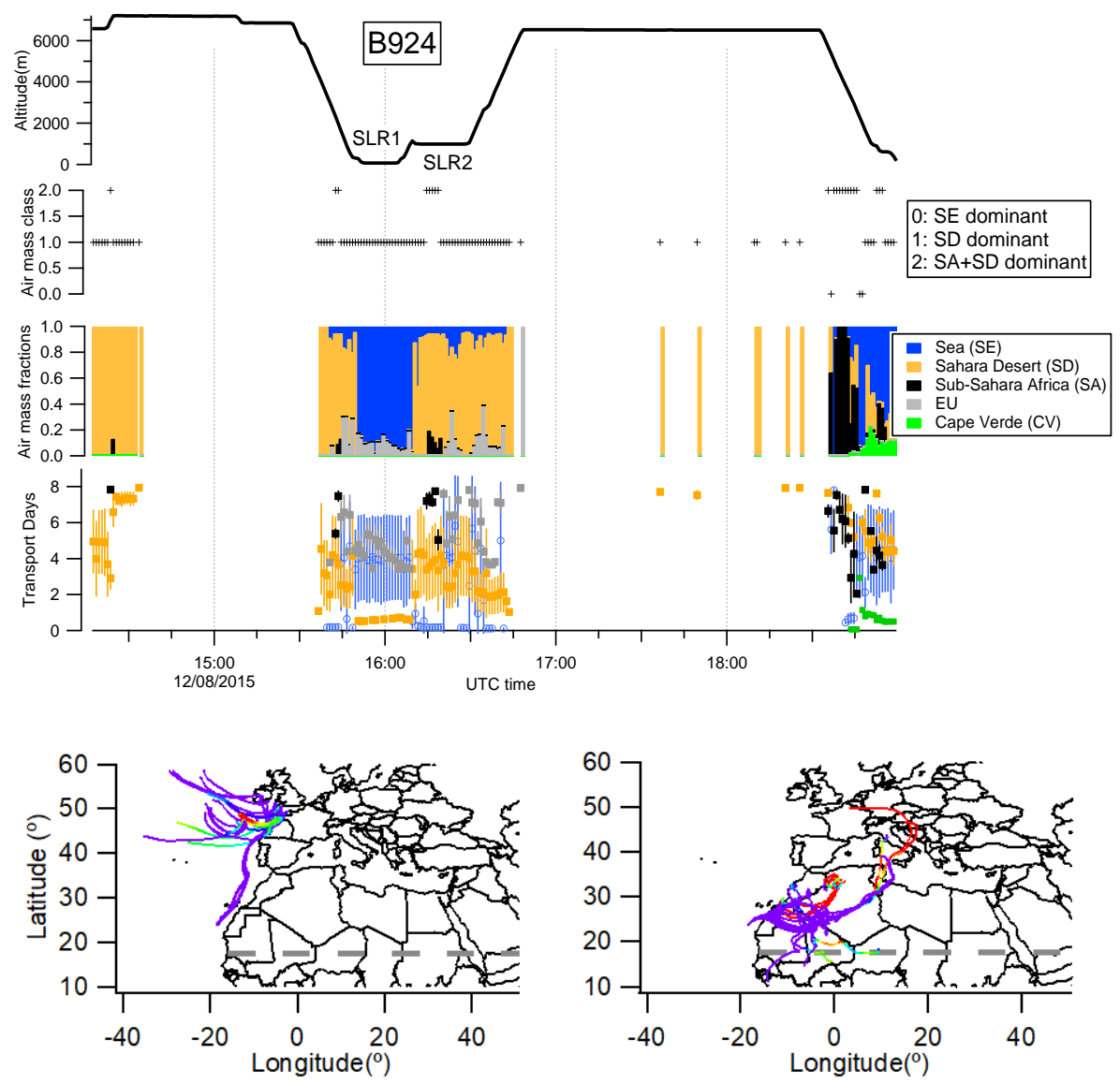

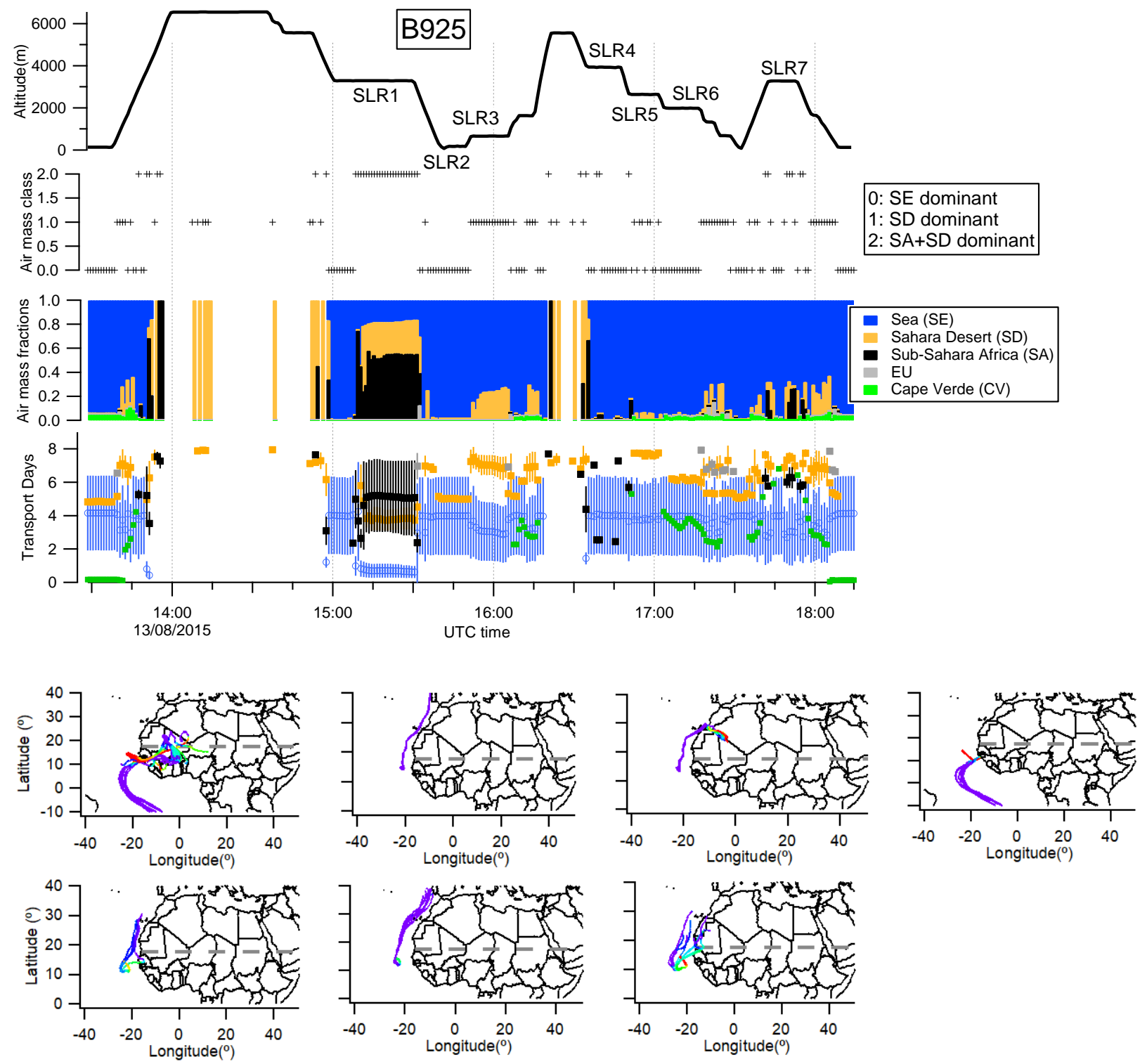

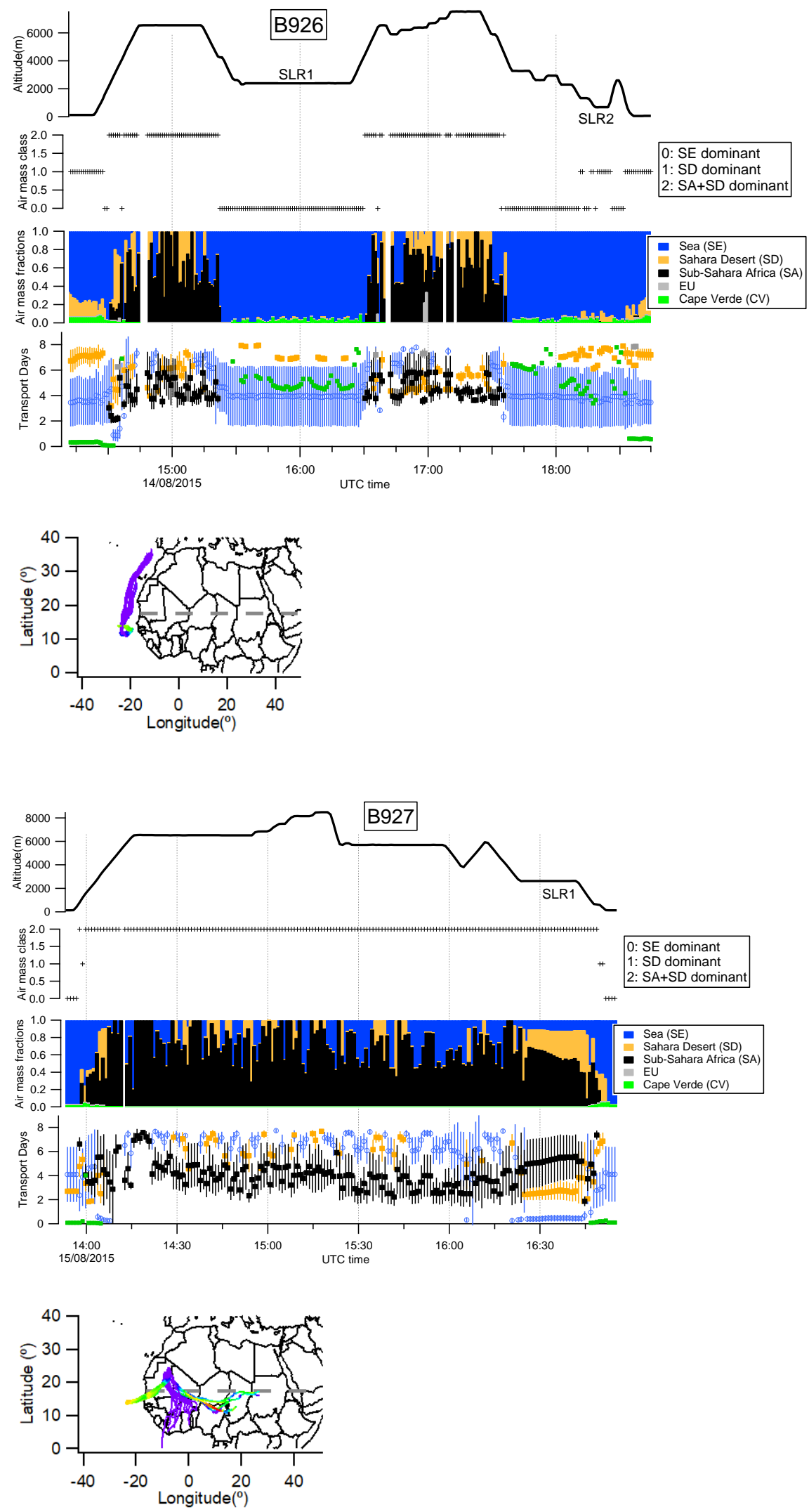

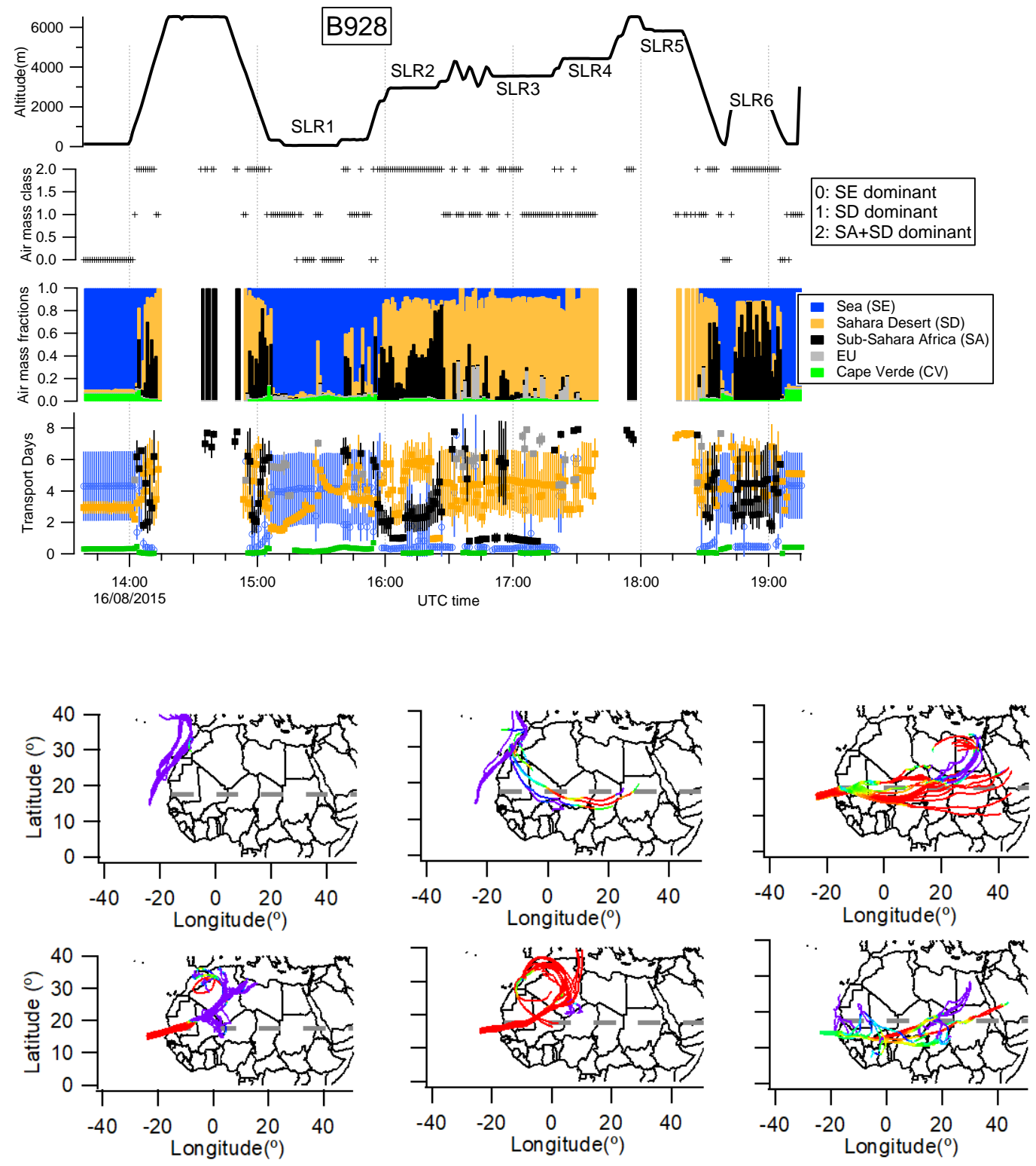

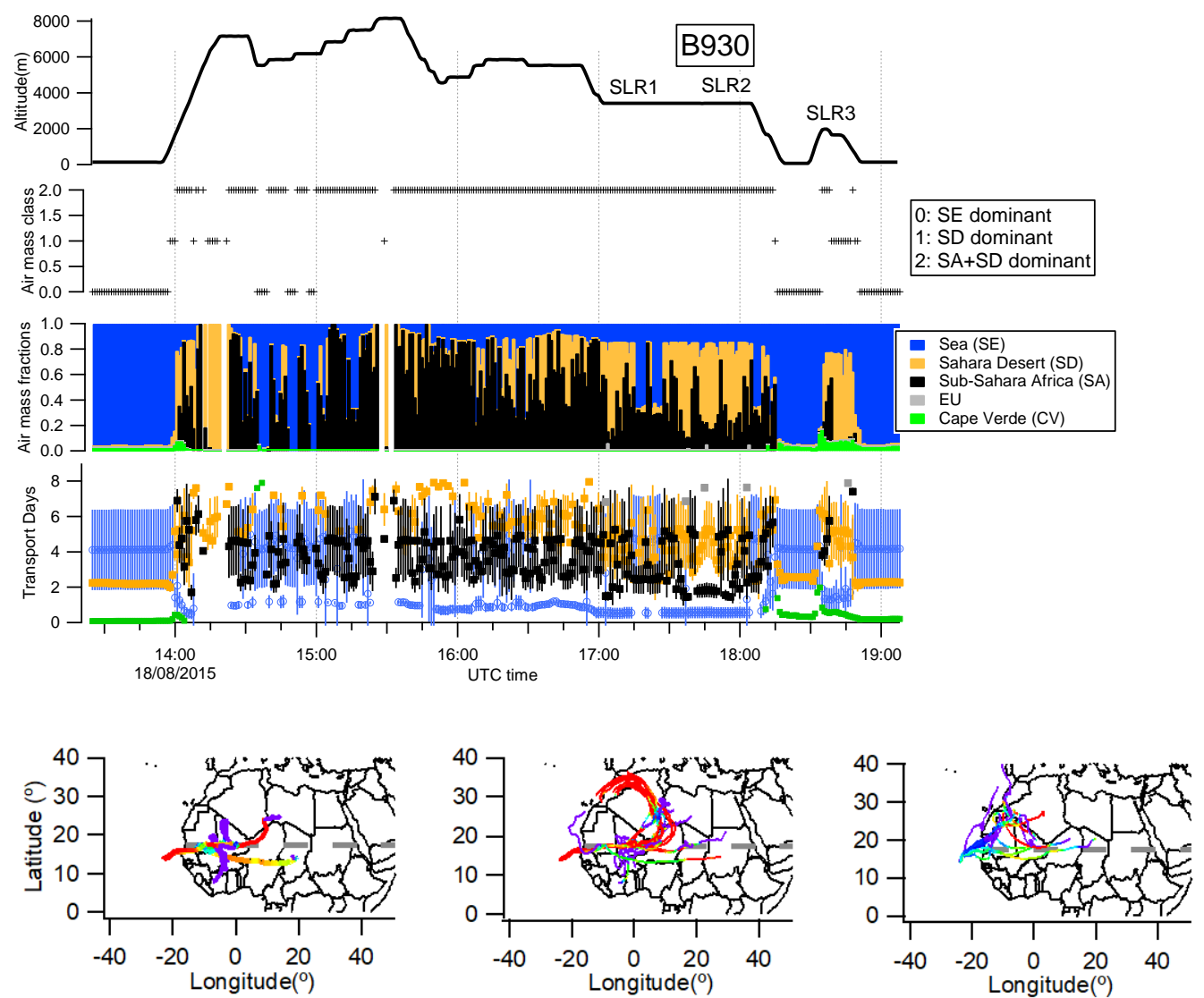

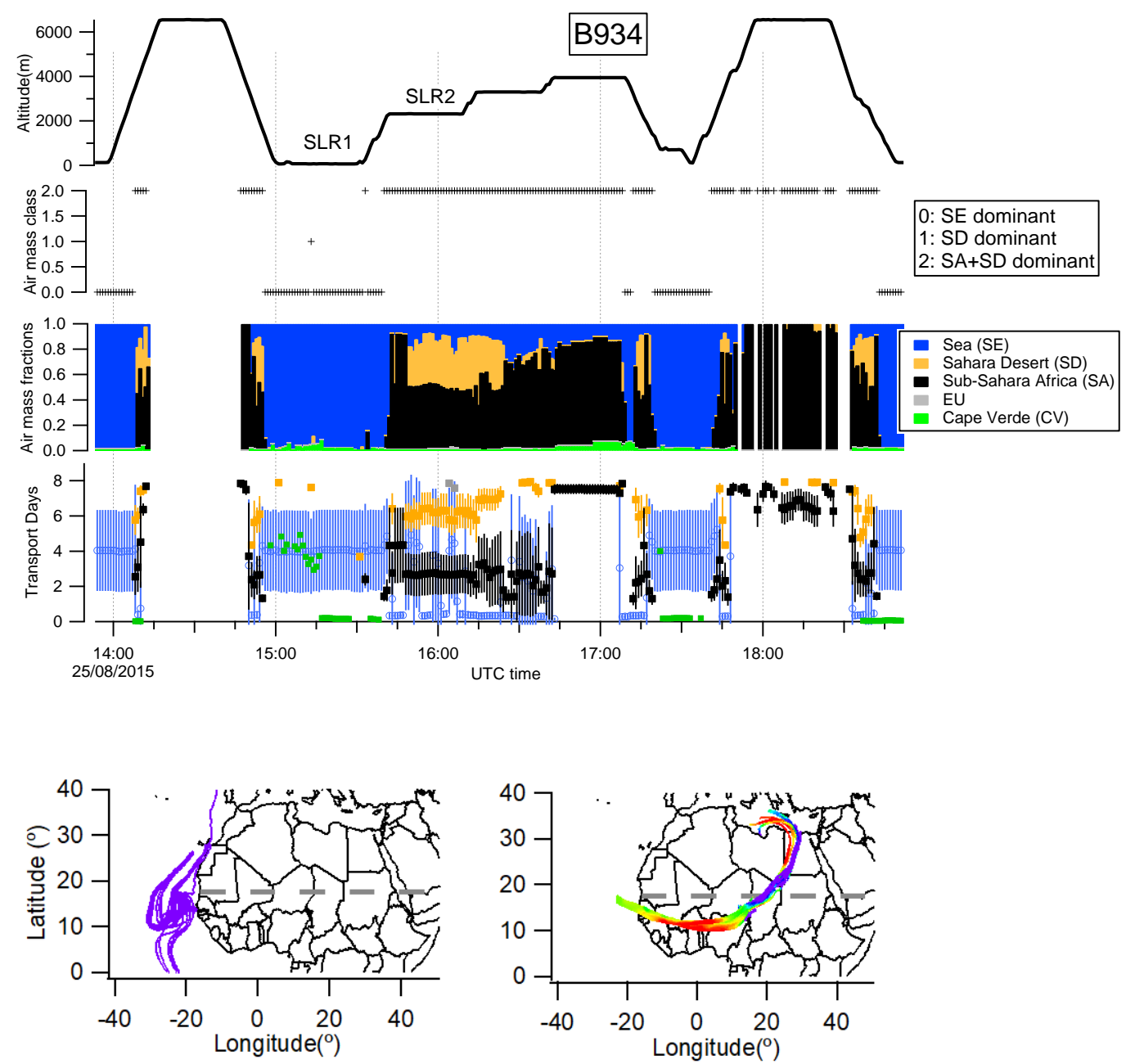

Fig. S7. For each flight, the top figure shows the results from backtrajectory analysis (identical with Fig. 6). Each of the sub-figure shows the corresponding backtrajectories for each SLR. 


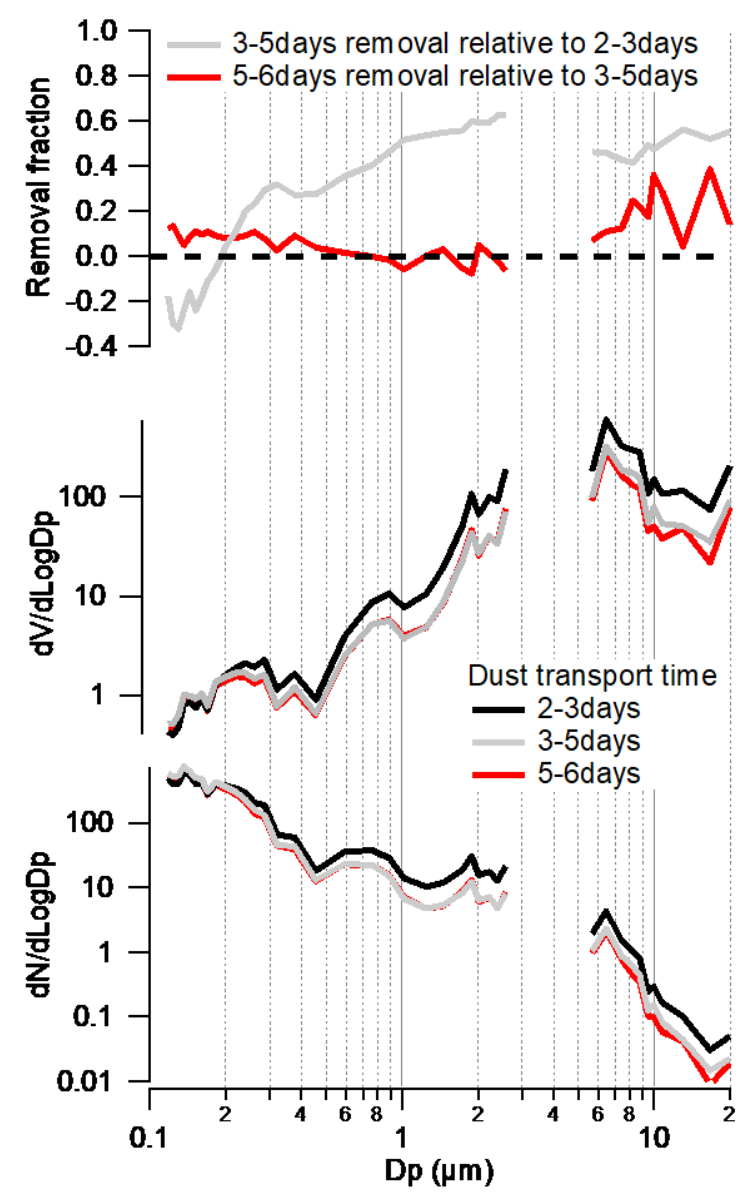

Fig. S8. The particle number and volume size distributions at $0.1-20 \mu \mathrm{m}$ at different scales of dust ages; the removal fraction of particles in number at dust age 3-5days and 5-6 days. 